\title{
Mapping Monthly Distribution of Daily Light Integrals across the Contiguous United States
}

Pamela C. Korczynski, ${ }^{1}$ Joanne Logan, ${ }^{2}$ and James E. Faust ${ }^{3}$

Additional Index words. daily photosynthetic photon flux density, light quantity, photosynthetically active radiation, solar radiation

Summary. The daily light integral (DLI) is a measurement of the total amount of photosynthetically active radiation delivered over a 24-hour period and is an important factor influencing plant growth over weeks and months. Contour maps were developed to demonstrate the mean DLI for each month of the year across the contiguous United States. The maps are based on 30 years of solar radiation data for 216 sites compiled and reported by the National Renewable Energy Lab in radiometric units (watt-hours per $\mathrm{m}^{-2} \cdot \mathrm{d}^{-1}$, from 300 to 3,000 nm) that we converted to quantum units $\left(\mathrm{mol} \cdot \mathrm{m}^{-2} \cdot \mathrm{d}^{-1}, 400\right.$ to $\left.700 \mathrm{~nm}\right)$. The mean DLI ranges from 5 to $10 \mathrm{~mol} \cdot \mathrm{m}^{-2} \cdot \mathrm{d}^{-1}$ across the northern U.S. in December to 55 to $60 \mathrm{~mol} \cdot \mathrm{m}^{-2} \cdot \mathrm{d}^{-1}$ in the southwestern U.S. in May through July. From October through February, the differences in DLI primarily occur between the northern and southern U.S., while from May through August the differences in DLI primarily occur between the eastern and western U.S. The DLI changes rapidly during the months before and after the vernal and autumnal equinoxes, e.g., increasing by more than $60 \%$ from February to April in many locations. The contour maps provide a means of estimating the typical DLI received across the U.S. throughout the year.

L ight is of fundamental importance in plant growth studies; however it is also arguably one of most difficult elements to discuss quantitatively. Most often sunlight is discussed in relative terms, such as high and low light. The closest that most commercial growers come to quantifying light measurements is to refer to the maximum amount of visible radiation delivered during a sunny day [e.g., 2,000 $\left.\mu \mathrm{mol} \cdot \mathrm{m}^{-2} \cdot \mathrm{s}^{-1}(10,000 \mathrm{fc})\right]$. Also, academic plant science articles frequently lack adequate radiation measurements. The challenges of quantifying radiant energy are a result of the many different measurement units used and the time and expense of purchasing and maintaining accurate sensors and data-recording equipment.

Radiation measurements can be expressed in photometric, radiometric and quantum units. Commercial growers are often most familiar with photometric units, e.g., footcandles, lux or lumens. However, photometric sensors are considered less acceptable for use by plant scientists because of the large variation in measurements recorded under the various available radiation sources (McCree, 1972; Pearcy, 1991).

\footnotetext{
The authors acknowledge the Clemson University and University of Tennessee Experiment Stations for their support of this project. We also thank the Bedding Plant Foundation Inc. for partial funding of this project.

${ }^{1}$ Department of Ornamental Horticulture and Landscape Design, University of Tennessee, Knoxville, TN 37901-1091.

${ }^{2}$ Department of Plant and Soil Science, University of Tennessee, Knoxville, TN 37901-1091.

${ }^{3}$ Department of Horticulture, Clemson University, Clemson, SC 29634-0375.
} 
Radiometric units (e.g., watts, joules, langleys, calories, and ergs) quantify the amount of energy contained within the radiation. Therefore, radiometric units are most useful for measuring sunlight as it relates to horticultural engineering purposes, such as greenhouse heating and cooling, evapotranspiration, and irrigation (Hanan, 1998).

Current guidelines recommend reporting the amount of radiant energy delivered during plant studies in quantum units, $\mu \mathrm{mol} \cdot \mathrm{m}^{-2} \cdot \mathrm{s}^{-1}$ (Krizek et al., 1997; Tibbitts, et al., 2000). Quantum units describe the number of light particles, or photons, delivered at wavelengths that contribute to photosynthesis (400 to $700 \mathrm{~nm})$. A mole refers to Avagadro's number $(6.023 \times$ $10^{23}$ ) of photons. Quantum sensors are designed to count the number of photosynthetically active photons and thus measure the radiation that could actually be used in photosynthesis. Therefore, quantum sensors are recommended to quantifying light as it relates to photosynthesis and plant growth.

Integrated light measurements involve the accumulation of per second quantum flux measurements over time. The integrated quantum unit recommended by ASHS is $\mathrm{mol} \cdot \mathrm{m}^{-2} \cdot \mathrm{d}^{-1}$, which describes the sum of the per second measurements during one 24$\mathrm{h}$ period. The unit, $\mathrm{mol} \cdot \mathrm{m}^{-2} \cdot \mathrm{d}^{-1}$, is most commonly referred to as the daily light integral.

The DLI averaged over weeks, months or seasons is a very useful measurement when the plant response of interest is plant growth or phenology (Pearcy, 1991). Numerous studies have reported plant responses to DLI. For example, the dry weight of miniature rose (Rosa $\times$ bybrida) (Mortensen and Moe, 1995), petunia (Petunia $\times$ bybrida)(Lieth et al., 1991), geranium (Pelargonium $\times$ hortorum) (White and Warrington, 1988), pansy (Viola $\times$ wittrockiana) (Niu et al., 2000), and marigold (Tagetes patula) (Armitage et al., 1981a) increased as DLI increased, although the rate of dry weight increase decreases as DLI increases. Stem diameter and number of shoots per plant of heliconia (Heliconia sp.) (Catley and Brooking, 1996) and oxypetulum (Oxypetulum sp.) (Armitage et al., 1990) increased as DLI increased. Also, total leaf chlorophyll and anthocyanin content of marigold increased as DLI increased (Armitage and Carlson, 1981). Leaf area and plant height typically increase as the DLI increases from very low levels (less than $5 \mathrm{~mol} \cdot \mathrm{m}^{-2} \cdot \mathrm{d}^{-1}$ ) to moderate levels $\left(20 \mathrm{~mol} \cdot \mathrm{m}^{-2} \cdot \mathrm{d}^{-1}\right)$ (Armitage et al., 1981a); however, leaf area and plant height decrease as DLI increases from moderate to relatively high levels $\left(30 \mathrm{~mol} \cdot \mathrm{m}^{-2} \cdot \mathrm{d}^{-1}\right)$ (Catley and Brooking, 1996; White and Warrington, 1984).

At a DLI less than $5 \mathrm{~mol} \cdot \mathrm{m}^{-2} \cdot \mathrm{d}^{-1}$, flowering is inhibited or delayed for african violets (Saintpaulia ionantha) (Faust and Heins, 1994), roses (Maas and Bakx, 1995), and geranium (Armitage et al., 1981b). Increasing the DLI from 5 to $10 \mathrm{~mol} \cdot \mathrm{m}^{-2} \cdot \mathrm{d}^{-1}$ has been shown to decrease the number of days to flower for geranium (Armitage et al., 1981b; Kaczperski et al., 1991); however, further increasing the DLI above $10 \mathrm{~mol} \cdot \mathrm{m}^{-2} \cdot \mathrm{d}^{-1}$ did not significantly effect the time to flower (Armitage et al., 1990, 1981b; White and Warrington, 1984). The DLI typically has a larger effect on time to visible flower bud appearance than on the time from visible flower bud to anthesis (Armitage et al., 1981a, 1981b); thus, it appears that DLI has a greater impact on flower initiation than on the rate of flower development.

Tables and maps, in various units and forms have been in use for the last half-century to quantify solar radiation across the U.S. (Crabb, 1950; Mastalerz, 1977; Rosenberg et al., 1983). Both radiometric or photometric units have been used to describe solar radiation depending on the purpose of the maps; however, to our knowledge, solar radiation maps using quantum units have not previously been developed. Therefore, the objective of this project was to develop a tool for horticulturists to estimate DLI delivered throughout the year across the contiguous U.S.

\section{Materials and methods}

Data for the DLI maps were collected from the daily statistics files contained in the National Solar Radiation Data Base maintained on a website by the Renewable Resource Data Center (RReDC) and the National Renewable Energy Lab (NREL), a subdivision of the United States Department of Energy (RReDC, 2001). Each statistics file contains 30 years (1961-
90) of global-horizontal radiation data reported in radiometric units (watthours per $\mathrm{m}^{-2} \cdot \mathrm{d}^{-1}$, total shortwave spectrum, 300 to $3,000 \mathrm{~nm}$ ). Data were collected at 56 primary sites by the National Weather Service, although the exact number of sites that provided useful data varied from year to year. The measurement instrumentation also varied over the years; however, the pyranometer (model 50; Eppley Laboratory, Newport, R.I.) was the standard sensor used at the weather stations. Missing data at the primary sites and data for the 160 secondary sites were estimated with the meteorological-statistical (METSTAT) solar radiation model developed by the NREL. These measured and modeled data were combined with meteorological data obtained from the National Climatic Data Center to create the $\mathrm{Na}$ tional Solar Radiation Data Base.

Monthly averages of daily total solar energy data were downloaded from the RReDC website for each of the 216 Weather Bureau Army Navy sites located in the 48 contiguous states (RReDC, 2001). The data were converted to quantum units $\left(\mathrm{mol} \cdot \mathrm{m}^{-2} \cdot \mathrm{d}^{-1}\right)$ using the conversion factor $7.058 \times$ $10^{-3} \mathrm{~mol} \cdot \mathrm{m}^{-2} \cdot \mathrm{d}^{-1}$ per watt-hours per $\mathrm{m}^{-2} \cdot \mathrm{d}^{-1}$. This conversion factor assumes $42.9 \%$ of the total solar radiation $(300$ to $3,000 \mathrm{~nm}$ ) is in the photosynthetically active radiation $(P A R)$ spectrum (400 to $700 \mathrm{~nm}$ ) and $4.57 \mu \mathrm{mol} \cdot \mathrm{m}^{-2} \cdot \mathrm{s}^{-1}$ per W.m- ${ }^{-2}(400$ to $700 \mathrm{~nm}$ ) (Thimijan and Heins, 1983).

A database containing the 30 year monthly DLI means was imported into Arcview GIS version 3.2 (Environmental Research Systems Institute, Inc., Redlands, Calif.). Since the 216 data points were not evenly distributed, the surface was interpolated for each month using the weighted inverse distance between the six nearest neighbors. Six neighbors were chosen because at this point the contours began to stabilize, i.e., lower numbers resulted in more erratic contours while higher numbers did not have much further impact on the existing contours. The $5 \mathrm{~mol} \cdot \mathrm{m}^{-2} \cdot \mathrm{d}^{-1}$ increment was chosen to be a useful division in the legend. This increment represents a value of about one-tenth the average total possible DLI $\left(60 \mathrm{~mol} \cdot \mathrm{m}^{-2} \cdot \mathrm{d}^{-1}\right)$.

\section{Results}

The contour maps display the monthly mean DLI delivered across 


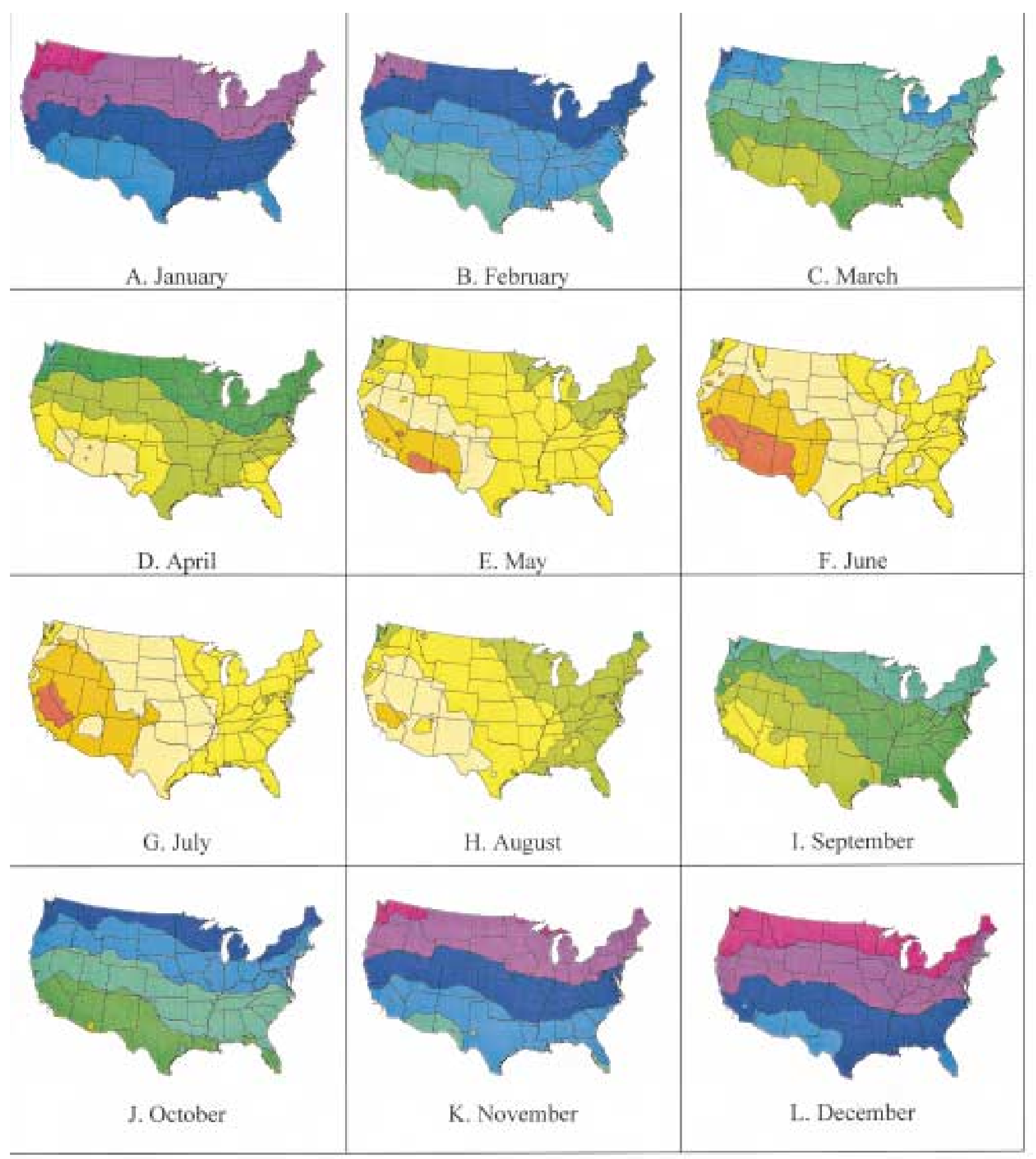

\begin{tabular}{|c|c|c|}
\hline \multicolumn{3}{|c|}{$\begin{array}{l}\text { Daily Light Integral } \\
\qquad\left(\mathrm{molm}^{-2} \mathrm{~d}^{-1}\right)\end{array}$} \\
\hline $\begin{array}{l}5-10 \\
10-15 \\
15-20 \\
20-25\end{array}$ & $\begin{array}{l}25-30 \\
30-35 \\
35-40\end{array}$ & $\begin{array}{l}40-45 \\
45-50 \\
50-55 \\
55-60\end{array}$ \\
\hline
\end{tabular}

Fig. 1. Contour maps displaying the mean daily light integral $\left(\mathrm{mol} \cdot \mathrm{m}^{-2} \cdot \mathrm{d}^{-1}\right)$ for each month of the year across the contiguous U.S. 
the 48 contiguous U.S. (Fig. 1). The effects of solar elevation angle, solar duration, surface elevation, and regional weather patterns on DLI are demonstrated in the contour maps. The contours display horizontal bands across the U.S from October through March (Fig. 1J-L, A-C). This pattern appears to be largely affected by solar duration and solar elevation angle. The solar duration is longer in the southern latitudes compared to the northern latitudes between 21 Sept. and 21 Mar. allowing for more time to accumulate a higher DLI. Also, the maximum quantum flux is higher in the southern latitudes throughout the year as a result of the increased solar elevation angle. Thus, the combination of longer solar duration and higher quantum fluxes across the southern U.S. result in higher DLI from October through March.

The primary DLI differences from May through August occur between the eastern and western U.S. (Fig. IE$\mathrm{H})$. These trends appear to be primarily the result of regional weather patterns during the summer, and to some extent due to elevation. For example, the southwestern U.S. typically experiences fewer cloudy days and lower air humidity, while higher elevations in parts of the western U.S. also contribute to higher quantum fluxes. The north-south differences disappear during the summer months because the effects of solar duration and solar elevation angle balance out at that time. The solar duration is longer at northern latitudes from 21 Mar. to 21 Sept., while the maximum quantum flux continues to be higher across the southern U.S. Thus, the southern U.S. has shorter days, but higher quantum fluxes compared to the northern U.S. Consequently, the DLI during June and July is similar in Florida compared to Maine, Louisiana compared to Minnesota, and Texas compared to Montana.

The most rapid DLI changes occur during the months surrounding the vernal and autumnal equinoxes (Fig. 1B-D, H-J). For example, the DLI in Columbia, Mo. increases from $21 \mathrm{~mol} \cdot \mathrm{m}^{-2} \cdot \mathrm{d}^{-1}$ in February to 37 $\mathrm{mol} \cdot \mathrm{m}^{-2} \cdot \mathrm{d}^{-1}$ in April and decreases from $42 \mathrm{~mol} \cdot \mathrm{m}^{-2} \cdot \mathrm{d}^{-1}$ in August to 25 $\mathrm{mol} \cdot \mathrm{m}^{-2} \cdot \mathrm{d}^{-1}$ in October. As a result, during the spring the DLI delivered to a southern U.S. location during 1 month is frequently similar to the DLI delivered to a northern U.S. location the following month. For example, the DLI is 30 to $35 \mathrm{~mol} \cdot \mathrm{m}^{-2} \cdot \mathrm{d}^{-1}$ in both Georgia in March and Michigan in April. Similarly, during the autumn the DLI is 25 to $30 \mathrm{~mol} \cdot \mathrm{m}^{-2} \cdot \mathrm{d}^{-1}$ in both Michigan in September and Georgia in October.

For any given location, the DLI delivered throughout the year roughly tracks the ambient solar duration. For example, the monthly mean DLI for Columbia, Missouri are 16, 21, 28, $37,42,47,47,42,33,25,16$, and 13 $\mathrm{mol} \cdot \mathrm{m}^{-2} \cdot \mathrm{d}^{-1}$, respectively from January through December, while the solar durations are 9.6, 10.5, 11.7, 13.0, $14.1,14.7,14.5,13.5,12.2,11.0$, $9.8,9.3$, respectively.

\section{Discussion}

The DLI maps generated from data compiled in the National Solar Radiation Data Base (RReDC, 2001) provide a useful basis for comparing the DLI across the U.S. with location and time of year; however, users must recognize that limitations exist. The National Solar Radiation Data Base relies heavily on data modeled from a limited number of locations in the contiguous U.S. The distribution of sites in the database provides reasonably thorough coverage of the U.S.; however, local microclimates occurring between those sites are not accounted for.

The interpolation method used to generate the maps also has its limitations. The inverse distance method takes into account the DLI at the six nearest locations. This procedure effectively acts to moderate variations in the data occurring at an isolated location whether they are real or artifacts. Thus, the database and the interpolation method used to generate the maps tend to minimize or potentially miss the effect of local microclimates. The result is a series of contour maps that show the general trends and variation in DLI that occur across the U.S. during the year.

Measurements can be made to compare local microclimates to the DLI maps or to determine the DLI inside greenhouses. However, dataloggers are needed to obtain an accurate record of quantum flux measurements over time so that DLI can be calculated.

The DLI maps can be used to estimate the contribution of supplemental lighting to the total DLI inside greenhouses throughout the year. For example, if high-pressure sodium lamps used in a commercial greenhouse provide $50 \mu \mathrm{mol} \cdot \mathrm{m}^{-2} \cdot \mathrm{s}^{-1}$ for $12 \mathrm{~h} \cdot \mathrm{d}^{-1}$, an additional $2.2 \mathrm{~mol} \cdot \mathrm{m}^{-2} \cdot \mathrm{d}^{-1}$ is delivered to the crop. This is not a particularly high large DLI. However, a northern U.S. greenhouse may average only 2.5 to $10.0 \mathrm{~mol} \cdot \mathrm{m}^{-2} \cdot \mathrm{d}^{-1}$ from November through February, assuming 50\% greenhouse transmission. Thus, under these conditions supplemental lighting can approximately provide a $22 \%$ to $88 \%$ increase in DLI compared to ambient greenhouse conditions.

To communicate effectively about plant responses to sunlight, there is a need for a clear definition from which to start. The DLI, expressed in the units of $\mathrm{mol} \cdot \mathrm{m}^{-2} \cdot \mathrm{d}^{-1}$, is a very useful measurement to describe whole-plant growth responses over weeks, months or seasons. Since measurements are often not available, the developed DLI maps provide an estimate of the light quantities received by different locations across the country. We anticipate that these maps will serve a useful purpose by facilitating the discussion of issues involving crop responses to DLI.

\section{Literature cited}

Armitage, A.M. and W.H. Carlson. 1981. The effect of quantum flux density, day and night temperature and phosphorus and potassium status on anthocyanin and chlorophyll content in marigold leaves. J. Amer. Soc. Hort. Sci. 106(5):639-642.

Armitage, A.M., W.H. Carlson, and C.E. Cress. 1981a. Determination of flowering time and vegetative habit of Tagetes patula through response surface techniques. J. Amer. Soc. Hort. Sci. 106(5):632-638.

Armitage, A.M., W.H. Carlson, and J.A. Flore. 1981b. The effect of temperature and quantum flux density on the morphology, physiology, and flowering of hybrid geraniums. J. Amer. Soc. Hort. Sci. 106(5):643-647.

Armitage, A.M., N.G. Seager, I.J. Warrington, D.H. Greer, and J. Reyngoud. 1990. Response of Oxypetalum caeruleum to irradiance, temperature, and photoperiod. J. Amer. Soc. Hort. Sci. 115(6):910 914.

Catley, J.L. and I.R. Brooking. 1996. Temperature and light influence growth and flower production in Heliconia 'Golden Torch'. HortScience 31(2):213-217.

Crabb, Jr., G. 1950. Solar radiation investigations in Michigan. Mich. State Univ. 
Agr. Expt. Sta. Tech. Bul. 222.

Faust, J.E. and R.D. Heins. 1994. Modeling inflorescence development of the African violet (Saintpaulia ionantha Wendl.). J. Amer. Soc. Hort. Sci. 199(4):727-734.

Hanan, J.J. 1998. Radiation, p. 91-166. In: Greenhouses: Advanced technology for protected horticulture. CRC Press, Boca Raton, Fla.

Kaczperski, M.P.,W.H. Carlson, and M.G. Karlsson. 1991. Growth and development of Petunia $\times$ bybrida as a function of temperature and irradiance. J. Amer. Soc. Hort. Sci. 116(2):232-237.

Lieth, J.H., R.H. Merritt, and H.C. Kohl, Jr. 1991. Crop productivity of petunia in relation to photosynthetically active radiation and air temperature. J. Amer. Soc. Hort. Sci. 116(4):623-626.

Krizek, D.T., J.C. Sager, and T.W. Tibbitts . 1997. Guidelines for measurement and reporting of environmental conditions, $\mathrm{p}$. 207-216. In: R.W. Langhans and T.W. Tibbitts (eds.). Plant growth chamber handbook. Iowa State Univ. N. Central Reg. Res. Publ. 340.

Maas, F.M. and E.J. Bakx. 1995. Effects of light on growth and flowering of Rosa bybrida 'Mercedes'. J. Amer. Soc. Hort. Sci. 120(4):571-576.

Mastalerz, J. 1977. The greenhouse light environment. Wiley, New York.

McCree, K.J. 1972. Test of current definitions of photosynthetically active radiation against leaf photosynthesis data. Agr. Meteorol. 10:443-53.

Mortensen, L. and R. Moe. 1995. Effects of temperature, carbon dioxide concentration, daylength and photon flux density on growth, morphogenesis and flowering of miniature roses. Acta Hort. 378:63-70.

Niu, G., R. Heins, A. Cameron, and W. Carlson. 2000. Day and night temperature, daily light integral, and $\mathrm{CO}_{2}$ enrichment affect growth and flower development of pansy (Viola Xwittrockiana). J. Amer. Soc. Hort. Sci. 125(4):436-441.

Pearcy, R.W. 1991. Radiation and light measurements, p.97-116. In: R.W. Pearcy, J. Ehleringer, H.A. Mooney, and P.W. Rundel (eds.). Plant physiological ecology: Field methods and instrumentation. Chapman and Hall, New York.

Renewable Resource Data Center. 2001. Solar radiation resource information. The national solar radiation data base. Daily statistics files. 1 Oct. 2001. <http:// www.rredc.nrel.gov/solar/>.

Rosenberg, N., B. Blad, and S. Verma. 1983. Microclimate: The biological environment. $2^{\text {nd }}$ ed. Wiley, New York.

Thimijan, R.W. and R.D. Heins. 1983. Photometric, radiometric and quantum light units for measure: A review of procedures for interconversion. HortScience $18(6): 818-822$.

Tibbitts, T.W., J.C. Sager, and D.T. Krizek. 2000. Guidelines for measuring and reporting environmental parameters in growth chambers. Biotronics 29:9-16.

White, J.W. and I.J. Warrington. 1988. Temperature and light integral effects on growth and flowering of hybrid geraniums. J. Amer. Soc. Hort. Sci. 113(3):354359 .

White, J.W. and I.J. Warrington. 1984. Growth and development responses of geranium to temperature, light integral, $\mathrm{CO}_{2}$, and chlormequat. J. Amer. Soc. Hort. Sci. 109(5):728-735. 